\title{
Accelerated corrosion tests on waste-gated turbocharger's adjustable and fixed end-links
}

\author{
K. Wilton-Smith, Z. Khan, A. Saeed \& M. Hadfield \\ Engineering and Computing, Bournemouth University, UK
}

\begin{abstract}
A turbocharger which has been mounted to a heavy duty automotive diesel engine can be subjected to various aggressive environments and a range of temperatures varying from ambient to $670^{\circ} \mathrm{C}$. Extreme operating environments and temperatures can initiate corrosion leading to the degradation of the components. The present research evaluates the corrosion resistance of the zinc-coated and stainless steel waste-gate end-links based on accelerated corrosion and dust particles tests, using an environmental test rig. Samples were exposed to the tests for 504 hours. Images of the specimens were captured to record corrosion build-up and its progression on the surfaces during the exposure time. These results were then used to evaluate the corrosion resistance ability of both, zinc coated fixed and stainless steel adjustable end-links. Accumulation of corrosion and the build-up of salt deposits were observed on both end-links during and after the experiments.

Keywords: accelerated corrosion, turbocharger, end-links, extreme environment.
\end{abstract}

\section{Introduction}

Mechanical component failures through surface degradation are often the result of corrosion (chemical/electrochemical) and wear mechanisms. Surface degradation due to corrosion arises through an attack of reactive compounds on surfaces and the subsequent product removal through a mechanical action. Mechanical degradation through wear is often the result of friction, abrasion, impact and fatigue. Failures because of corrosion and wear are time dependent and nonlinear. Surface degradation results in partial or complete component malfunction, higher maintenance costs and risks to the structural integrity [1-3].

This contribution presents the effects of corrosion and dust particles on the external turbocharger components stainless steel adjustable and zinc coated steel 
fixed end-links. This research is motivated by the turbocharger failure which occurs in service because of corrosion in the end-links. An end-link is a threaded rod integrated into the turbocharger waste-gate assembly. The end-link is threaded to the end of the waste-gate's actuator rod with the opposite end being attached to lever linkage of the waste-gate system, which is placed in a circlip shown in Fig. 1.

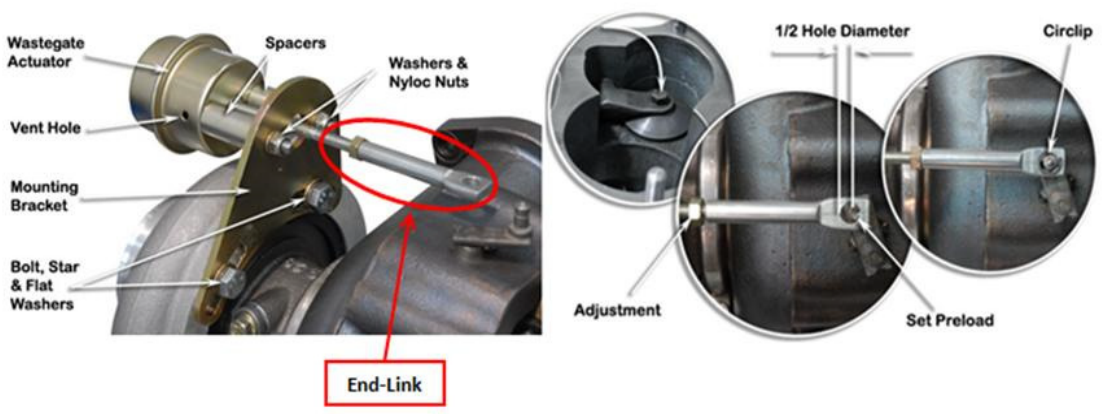

Figure 1: Turbocharger waste-gate assembly illustrating end-link locations (image courtesy of Safari Turbo).

The waste-gate assembly is a boost-controlling bypass value situated on the exhaust-end of the turbocharger. Waste-gate functions by limiting the exhaust gas passing through the turbine wheel of a turbocharged engine system. Waste-gate regulates the maximum boost pressure produced by the turbocharger to prevent and protect the turbocharged engine system from over-boosting. The energy produced is transferred back into the exhaust system of the turbine which in turn reduces the power driving the turbine wheel. This process helps the turbine wheel to match the required power for a given boost level. Turbocharger's turbine rotates at around $200 \mathrm{k} \mathrm{rpm}$, which is approximately 30 times faster than normal car engines. Since the turbine end is connected to the exhaust manifold of the engine, the temperature in the turbine reaches a value as high as $670^{\circ} \mathrm{C}$. Higher temperatures are a common cause of accelerated corrosion. During turbocharger operation, if the temperature is high, the materials will oxidise faster resulting in scaling. A thick scale formed because of overheating is critical to component degradation. As end-links are assembled within close proximity of the turbine housing, they are also subjected to high temperatures, as well as aggressive corrosive environments; these factors lead to accelerated component degradation $[4,5]$. For the prolong performance and lifetime of the turbocharger components, it is important to understand the materials utilised and the environment to which they are exposed. Environment plays a vital role in corrosion; the main factors responsible for corrosion are relative humidity $(\mathrm{RH})$, temperature, salts, pollutants concentration and time of wetness $[6,7]$.

To assess corrosion, field tests and laboratory based tests are performed. A field test involves exposure of the test specimen to the environment for a long period of time and that is the reason for being undesirable. Laboratory based corrosion tests involve increased corrosion activity to obtain results faster than field corrosion tests. Examples of laboratory based corrosion tests are simulated environmental 
and salt-spray cabinet corrosion test. These laboratory tests must be able to keep the corrosion mechanism identical to the field corrosion tests [8-10]. Results of accelerated corrosion tests on the waste-gated adjustable and fixed end-links are reported in this contribution.

\section{Experimental methodology}

\subsection{Samples exposure}

The experiment was conducted for 504 hours in total. 45 samples of each zinc coated and stainless steel end-links were exposed to the accelerated corrosion test. All the samples were inserted in the corrosion chamber simultaneously. Images of the samples were recorded at 18th, 26th, 92nd and 115th hour of exposure. The corrosion test was suspended at the 252nd hour, when 15 samples of each zinc coated and stainless steel were removed from the chamber in order to evaluate corrosion accumulation and their operating performance. The test was then resumed for another 252 hours as normal and images were captured at 278th, 305th, 352nd, 447th, 471st and 504th hour of exposure. The corrosion test was completed after 504 hours and all the samples were removed to evaluate corrosion build-up and their operational performance.

\subsection{Corrosion chamber and test conditions}

Accelerated corrosion tests were performed utilising a -330 environmental chamber shown in Fig. 2.

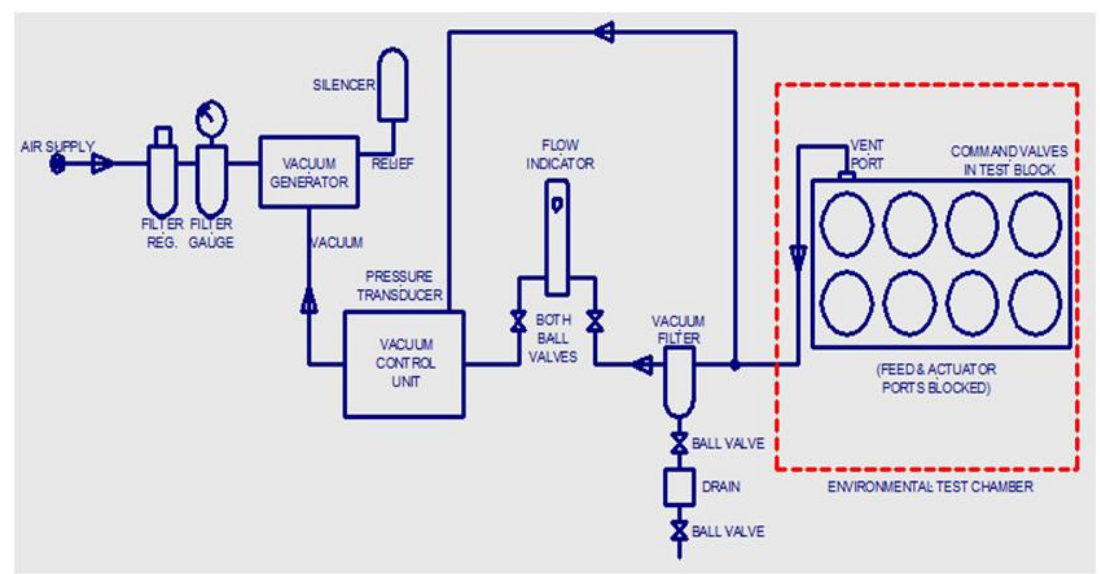

Figure 2: $\quad$ Schematic of the -330 environmental chamber.

The environmental chamber test was run under salt-spray accelerated corrosion (ASTM B 117) and Arizona test dust (ISO 12103 - A1) conditions simultaneously. Non-metallic separators were used to avoid contact among the samples during the test, as illustrated in Fig. 3. 


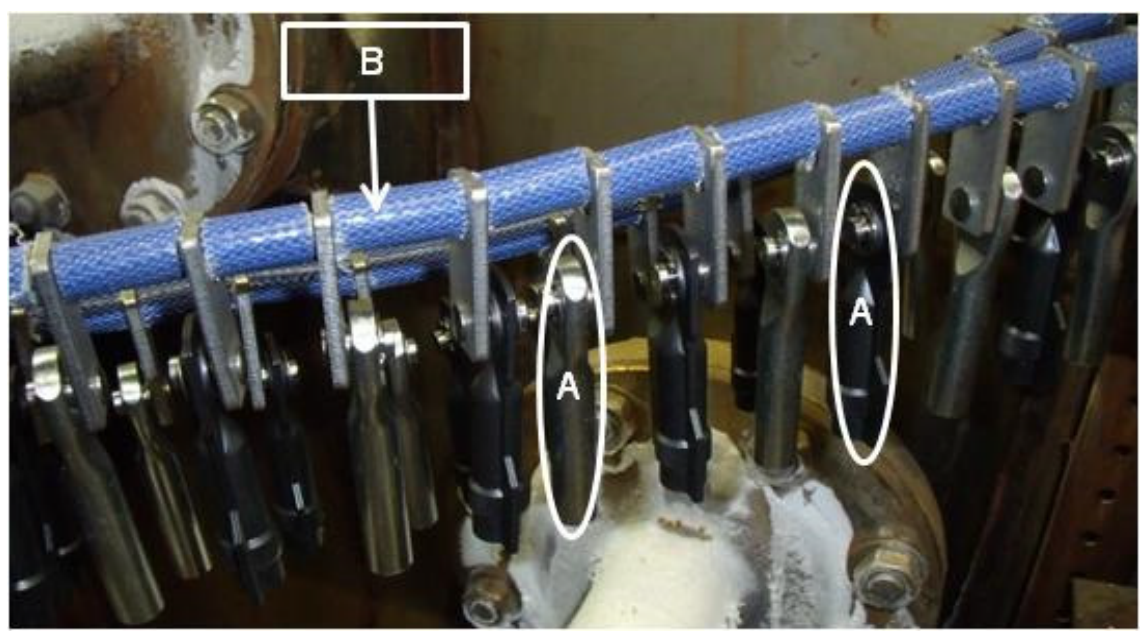

Figure 3: End-links exposure during corrosion test in the chamber (A) shows end-links; (B) shows none-metallic separator among the samples.

ASTM B117 is mainly used to evaluate corrosion resistance of the painted or metal coated samples. The salt solution contains dissolved $5 \%$ sodium chloride in distilled water in a $\mathrm{pH}$ range of 6.5-7.2 atomised as a fog into the chamber kept at $35^{\circ} \mathrm{C}$. Sodium chloride should be free from copper and nickel and may not contain more than $0.1 \%$ of sodium iodide [11].

ISO 12103 specifies four grades of test dusts made form desert sand. Desert sand is composed of compounds that motor vehicles are normally exposed to. The performance of the filtration systems can be evaluated through this test. However, in this test, sand particles are utilised and sand particles possess abrasive characteristics; for that reason, this test is also used in wear studies of bearings, seals, windshield wipers, etc. [12].

\section{Results and discussion}

The aim of this study was to evaluate the operating performance of the turbocharger end-links when operated under extreme environment and exposed to dust particles. Just after 18 hours of exposure the samples were inspected. Zinc coated samples showed the accumulation of salt deposits whereas initiation of corrosion was observed on the stainless steel end-links shown in Fig. 4.

After 138 of exposure, thicker salt deposits on zinc coated end-links were observed. Stainless steel samples exhibited good resistance to salt accumulation however a slight increase in corrosion build-up was noticed. 15 samples of each kind of end-links were removed from the chamber after 252 hours of exposure in order to evaluate their operating performance and subsequent salt and corrosion accumulation. After 252 hours of exposure, the zinc coated end-links showed 

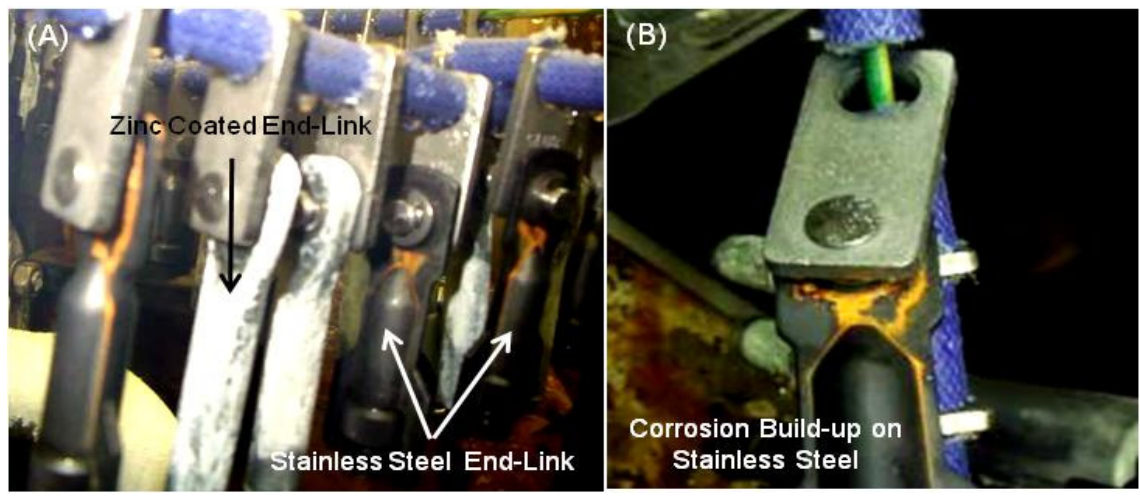

Figure 4: (A) Sample condition after 18 hours of exposure illustrate salt deposits on zinc coated and corrosion build-up on stainless steel endlinks; (B) close up of the stainless steel end-link.

accumulation of thicker salt deposits and the initiation of corrosion. However, stainless steel end-links had no salt deposit formation on their surfaces. The performance of both kinds of end-links was evaluated through a functionality test; the movement of the zinc coated ones was observed to be restricted because of the salt and corrosion deposits. The stainless steel ones, however, showed free movement and were fully functional. Formation of red rust was observed after 447 hours on almost every sample exposed to the test shown in Fig. 5.

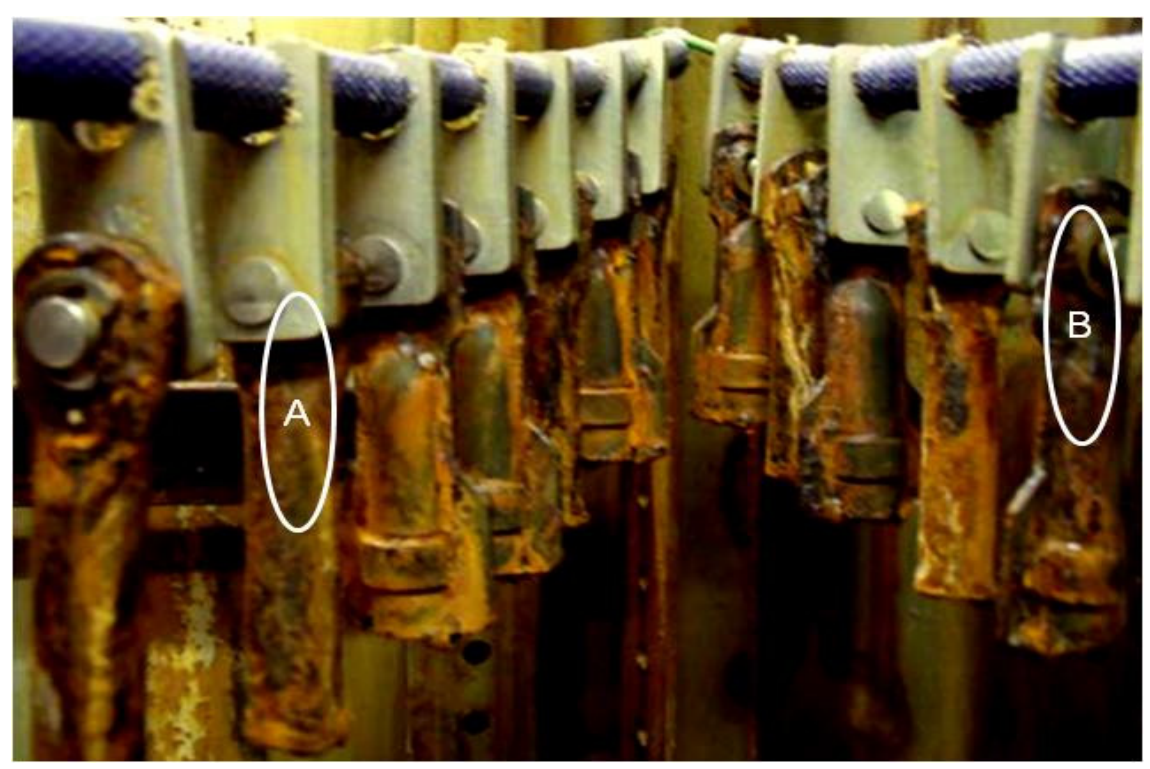

Figure 5: $\quad$ Sample exposure for 447 hours of the test; (A) and (B) indicate zinc coated and stainless steel end-links, respectively. 
The test was terminated at 504 hours of operation. All the samples showed formation of red rust on their surface, however no salt deposits were observed on the stainless steel ones. The operation of both kinds of end-links was evaluated after test completion. The stainless steel samples exhibited good performance and were fully functional. However zinc coated end-links failed to operate.

Zinc coating provides good protection for iron and steel products from corrosion in various environmental conditions. Zinc coating has the ability to form a dense, adherent corrosion product film on metal surfaces keeping the corrosion rate considerably low. Zinc is more reactive compared to iron on ambient conditions but a thin film of corrosion products develops resulting in the reduction of corrosion rate of iron $[13,14]$. The thick layer of corrosion products on the zinc coated end-links could be attributed to such characteristics of the zinc coating. However, the formation of the thick layer on the surface has led to the component failure in-terms of operating performance.

Stainless steel is widely in use due its ability to resist corrosion. For that reason the use of stainless steel is growing in both domestic and industrial applications. Stainless steel forms a thin invisible passive layer in oxygen-containing environments. This passive film is normally chromium oxide, which protects the surface against corrosion. For the creation of chromium oxide layer on the surfaces, chromium in the range of $16-28 \mathrm{wt} \%$ is added to stainless steel. Complete or partial breakdown of the chromium oxide layer leads to the corrosion of stainless steel. Localised breakdown of the passive film causes pitting or crevice corrosion while failures in the passive film on a larger scale often cause uniform corrosion. Solutions with low or high $\mathrm{pH}$ result in the breakdown of passive layer on a larger scale and the subsequent corrosion propagation is determined by the corrosive environment $[15,16]$. During the salt fog test, the $\mathrm{pH}$ was kept between 6.5 to 7.2 at $35^{\circ} \mathrm{C}$ and $5 \%$ salt solution. Corrosion accumulation on stainless steel end-links is attributed to the conditions when the $\mathrm{pH}$ was less or greater than $\mathrm{pH}$ 7. Environments containing chlorides make the metals more susceptible to corrosion [17]. 5\% of salt is more than found in sea water and therefore has increased the conductivity of the electrolyte on surfaces of the samples resulting in accelerated corrosion. Salts provide points of corrosion nucleation, keep the surfaces wet for longer time at lower relative humidity, and salt makes the electrolyte conductive thus increasing corrosion [18-20]. Higher salt containing environments have resulted in accelerated corrosion on both end-links.

\section{Conclusion}

The purpose of these tests was to evaluate the corrosion resistance of end-links when exposed to extreme environmental conditions and their ability to function when operated in an environment containing dust particles. Both zinc coated and stainless steel end-links accumulated corrosion during the test. Nonetheless, in terms of operation, stainless steel showed enhanced performance compared to zinc coated end-links. The performance of zinc coated end-links was compromised by exposing them to extreme environmental and working conditions. 


\section{References}

[1] Wood, R.J.K., Tribocorrosion. Shreir's Corrosion, ed. J.A.R. Tony, Elsevier: Oxford, pp. 1005-1050, 2010.

[2] Saeed, A., Khan, Z., Garland, N. \& Smith, R., Material characterisation to understand various modes of corrosion failures in large military vehicles of historical importance. WIT Transactions on Engineering Sciences, 72, eds. A.A. Mammoli, C.A. Brebbia \& A. Klem, pp. 95-106, 2011.

[3] Scott, D. Wear analysis. Physics in Technology, 14, pp. 133-139, 1983.

[4] Cummins Turbo Technologies, http://www.holset.co.uk/mainsite/files/ 3 4-Technical $\% 20$ Papers.php

[5] Safari $4 \times 4$ Engineering, Safari Power. http://www.safarisnorkel.com/ turbo/ turbo product.htm

[6] Schweitzer, P.A., Fundamentals of Corrosion: Mechanisms, Causes and Preventative Methods, CRC: Boca Raton, Fla., 2010.

[7] Ahmad, Z., Principles of Corrosion Engineering and Corrosion Control, Basic concepts in corrosion, Butterworth-Heinemann: Oxford, pp. 9-56, 2006.

[8] Schmidt, D.P., Shaw, B.A., Sikora, E., Shaw, W.W. \& Laliberte, L.H., Comparison of testing techniques used to analyze the corrosion resistance of sacrificial coating systems. Corrosion, 63, pp. 958-974, 2007.

[9] ASTM International, ASTM G85-11, Standard Practice for Modified Salt Spray (Fog) Testing.

[10] Boelen, B., Schmitz, B., Defourny, J. \& Blekkenhorst, F., A literature survey on the development of an accelerated laboratory test method for atmospheric corrosion of precoated steel products. Corrosion Science, 34, pp. 1923-1931, 1993.

[11] ASTM International, ASTM B 117-16, Standard Practice for Operating Salt Spray (Fog) Apparatus, pp. 1-12, 2011.

[12] BS ISO 12103-1:1997, Road Vehicles - Test Contaminants for Filter Evaluation -Part 1: Arizona Test Dust, BSI - British Standards Institution, pp. 1-6, 1997.

[13] Corrosion Doctors, Rust chemisty. Online: http://corrosion-doctors.org/ Experiments/rust-chemistry.htm

[14] Marder, A.R., The metallurgy of zinc-coated steel. Progress in Materials Science, 45, pp. 191-271, 2000.

[15] Iversen, A. \& Leffler, B., Aqueous corrosion of stainless steels. Shreir's Corrosion, vol. 3, eds. B. Cottis, M. Graham, R. Lindsay, S. Lyon, T. Richardson, D. Scantlebury \& H. Stott, Elsevier: Amsterdam, pp. 1802-1878, 2010.

[16] Truman, J.E., Coleman, M.J. \& Pirt, K.R., Note on influence of nitrogen content on resistance to pitting corrosion of stainless steels. British Corrosion Journal, 12, pp. 236-238, 1977.

[17] Nishikata, A., Yamashita, Y., Katayama, H., Tsuru, T., Usami, a., Tanabe, K. \& Mabuchi, H., An electrochemical impedance study on atmospheric 
corrosion of steels in a cyclic wet-dry condition. Corrosion Science, 37(12), pp. 2059-2069, 1995.

[18] Corvo, F., Mendoza, A.R., Autie, M. \& Betancourt, N., Role of water adsorption and salt content in atmospheric corrosion products of steel. Corrosion Science, 39, pp. 815-820, 1997.

[19] Saeed, A., Khan, Z. \& Montgomery, E., Corrosion damage analysis and material characterization of Sherman and Centaur - The historic military tanks. Materials Performance and Characterization, 2, pp. 30-44, 2013.

[20] Neufeld, A.K., Cole, I.S., Bond, A.M. \& Furman, S. A., The initiation mechanism of corrosion of zinc by sodium chloride particle deposition. Corrosion Science, 44, pp. 555-572, 2002. 